\title{
Determination of Ecstasy Components in Human Urine by Gas Chromatography using a Dispersive Liquid-Liquid Microextraction Procedure
}

\author{
Hossein Ali Mashayekhi*,a and Mohammad Rezaee ${ }^{b}$ \\ ${ }^{a}$ Department of Chemistry, Tonekabon Branch, Islamic Azad University, Tonekabon, Iran \\ ${ }^{b}$ Young Researchers Club, North Tehran Branch, Islamic Azad University, Tehran, Iran
}

\begin{abstract}
Um método novo foi desenvolvido para pré-concentração e determinação de compostos de ecstasy, 3,4-metilenodioxiamfetamina (MDA), 3,4-metilenodioximetilamfetamina (MDMA), 3,4-metilenodioxietilamfetamina (MDEA) e 3,4-metilenodioxipropilamfetamina (MDPA), em amostras de urina utilizando microextração líquido-líquido dispersiva (DLLME) e cromatografia gasosa com detector por ionização em chama (GC-FID). O método foi baseado na formação de gotículas de um extratante orgânico em soluções preparadas utilizando água, solvente orgânico imiscível $\left(\mathrm{CS}_{2}\right)$ dissolvido em solvente dispersor miscível em água (acetona). A fase orgânica, que extraiu MDA, MDEA, MDMA e MDPA da solução da amostra preparada, foi separada por centrifugação. Parâmetros que afetam a eficiência da extração foram investigados e otimizados. Sob condições ideais, as linearidades do método foram 1,0-500 $\mu \mathrm{g} \mathrm{L}-1$ para MDEA e MDPA e 2,5-500 $\mu \mathrm{g} \mathrm{L}$-1 para MDA e MDMA. Os limites de deteç̧ão (LOD, $\mathrm{S} / \mathrm{N}=3$, razão sinal ruído) foram no intervo de 0,3 a $0,8 \mu \mathrm{g} \mathrm{L} \mathrm{L}^{-1}$. O método foi aplicado com sucesso na determinação de analitos em amostras de urina.
\end{abstract}

A new method was developed for preconcentration and determination of ecstasy compounds, 3,4-methylenedioxyamphetamine (MDA), 3,4-methylenedioxymethylamphetamine (MDMA), 3,4-methylenedioxyethylamphetamine (MDEA) and 3,4-methylenedioxypropylamphetamine (MDPA), in urine samples using dispersive liquid-liquid microextraction (DLLME) and gas chromatography (GC) with flame ionization detection (GC-FID). The method was based on the formation of tiny droplets of an organic extractant in prepared sample solution using water, immiscible organic solvent $\left(\mathrm{CS}_{2}\right)$ dissolved in water-miscible organic disperser solvent (acetone). The organic phase, which extracted MDA, MDEA, MDMA and MDPA from the prepared sample solution, was separated by centrifugation. Parameters affecting extraction efficiency were investigated and optimized. Under the optimum conditions, linearities of the method were 1.0-500 $\mu \mathrm{g} \mathrm{L}^{-1}$ for MDEA and MDPA and 2.5-500 $\mu \mathrm{g} \mathrm{L}^{-1}$ for MDA and MDMA. The limits of detection (LODs, $\mathrm{S} / \mathrm{N}=3$, signal-to-noise ratio) were in the range from 0.3 to $0.8 \mu \mathrm{g} \mathrm{L}^{-1}$. The method was successfully applied to the determination of analytes in urine samples.

Keywords: dispersive liquid-liquid microextraction, ecstasy, amphetamine, urine samples, gas chromatography

\section{Introduction}

Amphetamines and other related derivatives are powerful stimulants of the central nervous system, often misused by recreational users. A chronic abuse of amphetamines often leads to hallucinations and psychosis, as well as to dysphoria and depression upon withdrawal. ${ }^{1}$ Therefore, their dosage in biological matrices, especially in urine, remains a big challenge for analytical chemists. For many years, immunoassays were largely applied to the dosage of

*e-mail: chem.mashayekhi@tonekaboniau.ac.ir amphetamine and related drugs. ${ }^{2}$ However, such methods are not specific enough and positive results have always to be confirmed by a second more specific technique. Consequently, several gas ${ }^{3,4}$ and liquid ${ }^{5}$ chromatographic methods have been developed for the determination of amphetamine and related compounds in biological matrices. However, the biological component is complex and analytes are usually present at low concentration in body. Therefore, sample preconcentration and clean up must be carried out before analyte can be determined by high-performance liquid chromatography (HPLC) or gas chromatography (GC). To eliminate interferences from the biological matrices, 
liquid-liquid extraction (LLE) and solid-phase extraction (SPE) have been proposed for the clean up step frequently. ${ }^{6,7}$ LLE involves multiple time-consuming steps and requires large volumes of organic solvent which costs high and is dangerous to environment and human. Although SPE requires less solvent and shorter preparation time than LLE, SPE and its cartridges are also rather expensive. Both above processes involve manipulation of samples, and therefore, they will be subject to human errors. In order words, any clean-up procedure may cause partial loss of analyte and consumption of labor, time and cost. Solid-phase microextraction (SPME) integrates sampling, extraction, concentration and sample introduction into a single step and offers a simple, solvent free alternative to traditional methods for sample preparation. SPME for determination of amphetamine and methamphetamine in urine has been used. ${ }^{89}$ However, SPME is also expensive, its fiber is fragile and has limited life-time and sample carry-over can be a problem. ${ }^{10}$

Dispersive liquid-liquid microextraction (DLLME) was introduced by Rezaee et al. ${ }^{11}$ in 2006. In this method, a cloudy solution is formed when an appropriate mixture of extraction and disperser solvents is injected into an aqueous sample containing the analytes of interest. The surface areas between extraction solvent and sample solution are infinitely large initially. Therefore, the extraction equilibrium can be achieved quickly. After extraction, phase separation is performed by centrifugation and the enriched analyte in the sedimented phase is determined by chromatographic or spectrometric methods. Due to its advantages such as simplicity, fast analysis, low cost and high extraction efficiency, the method has been applied for the determination of trace analytes in various samples. ${ }^{12-18}$

In the present work, it is used the DLLME technique and GC-FID for the simultaneous determination of 3,4-methylenedioxyamphetamine (MDA), 3,4-methylenedioxymethylamphetamine (MDMA), 3,4-methylenedioxyethylamphetamine (MDEA) and 3,4-methylenedioxypropylamphetamine (MDPA) in urine. Different parameters affecting the extraction process were studied and optimized in detail. The recommended method was successfully employed to determine target analytes in urine. To our knowledge, it is the first time the coupling of DLLME with GC for the determination of these ecstasy compounds in urine samples has been performed.

\section{Experimental}

\section{Chemicals and reagents}

All chemicals were of analytical reagent grade. Stock solutions of MDA, MDEA, MDMA and MDPA (Salars,
Como, Italy) were prepared in methanol at a concentration of $1 \mathrm{mg} \mathrm{mL} \mathrm{m}^{-1}$ and stored at $-18{ }^{\circ} \mathrm{C}$. Working solutions of standards at suitable concentrations were prepared every day from the stock solution. Carbon disulfide, carbon tetrachloride, chloroform and chlorobenzene as extraction solvents and acetone, acetonitrile and methanol as disperser solvents were obtained from Merck Company (Germany). Also, sodium chloride was purchased from Merck. The water used was purified by an Aqua Max-Ultra Youngling ultra-pure water purification system (Korea).

\section{Apparatus}

A gas chromatograph (Agilent GC-7890) equipped with a split/splitless injector system and flame ionization detector was used for separation and determination of the target analytes. Ultra pure helium gas $(99.999 \%$, Air products, UK) was passed through a molecular sieve and oxygen trap (Crs, USA), and it was used as carrier gas with a flow rate of $2 \mathrm{~mL} \mathrm{~min}{ }^{-1}$. The injection port was held at $260{ }^{\circ} \mathrm{C}$ and operated in the splitless mode for $1 \mathrm{~min}$ then split valve was opened and split ratio of 1:5 was applied. Separation was carried out on a DB5, $25 \mathrm{~m} \times 0.32 \mathrm{~mm}$ i.d. and $0.25 \mu \mathrm{m}$ film thickness from SGE (Victoria, Australia) capillary column. The oven temperature was kept at $80^{\circ} \mathrm{C}$ for 2 min and then increased to $200^{\circ} \mathrm{C}$ at the rate of $8{ }^{\circ} \mathrm{C} \mathrm{min}^{-1}$, and then increased to $260^{\circ} \mathrm{C}$ at the rate of $30^{\circ} \mathrm{C} \mathrm{min}^{-1}$ and was held for $2 \mathrm{~min}$. The FID oven temperature was maintained at $280{ }^{\circ} \mathrm{C}$. Hydrogen was generated by hydrogen generator (OPGU-2200S, Shimadzu) for FID at a flow rate of

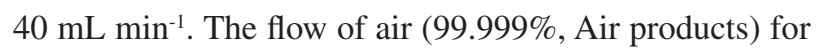
FID was $400 \mathrm{~mL} \mathrm{~min}^{-1}$.

\section{Dispersive liquid-liquid microextraction procedure}

The $\mathrm{pH}$ value of a $5.0 \mathrm{~mL}$ of prepared sample solution was adjusted to 10 with $1.0 \mathrm{~mol} \mathrm{~L}^{-1} \mathrm{NaOH}$ and the solution was placed in a $10 \mathrm{~mL}$ glass test tube with conical bottom. $1.0 \mathrm{~mL}$ of acetone (disperser solvent) containing $30.0 \mu \mathrm{L}$ of $\mathrm{CS}_{2}$ (extraction solvent) was injected rapidly into the sample solution by using a $2.5 \mathrm{~mL}$ syringe. A cloudy solution (water, acetone and $\mathrm{CS}_{2}$ ) was formed in the test tube. In this step, the analytes were extracted into the very fine droplets of $\mathrm{CS}_{2}$ in a few seconds. After centrifugation for $3 \mathrm{~min}$ at $3000 \mathrm{rpm}$, the extraction solvent was sedimented at the bottom of the conical test tube (about $5.0 \pm 0.1 \mu \mathrm{L}$ ). The volume of $2 \mu \mathrm{L}$ of organic solvent was injected into GC-FID instrument.

\section{Experimental-optimization parameters}

In order to obtain the best extraction performance, different parameters affecting the extraction process 
such as the kind and volume of extraction and disperser solvents, the $\mathrm{pH}$ value of sample solution were studied and optimized. Preconcentration factor (PF) and extraction recovery (ER) as analytical responses were calculated based on the following equations:

$$
\begin{aligned}
& \mathrm{PF}=\frac{\mathrm{C}_{\text {sedimented }}}{\mathrm{C}_{0}} \\
& \mathrm{ER}(\%)=\frac{\mathrm{C}_{\text {sedimented }} \times \mathrm{V}_{\text {sedimented }}}{\mathrm{C}_{0} \times \mathrm{V}_{\text {sample }}} \times 100=\mathrm{PF} \times \frac{\mathrm{V}_{\text {sedimented }}}{\mathrm{V}_{\text {sample }}} \times 100
\end{aligned}
$$

where, $\mathrm{PF}, \mathrm{C}_{\mathrm{se}}$ and $\mathrm{C}_{0}$ are the preconcentration factor, analyte concentration in the sedimented phase and initial analyte concentration in the sample, respectively; ER (\%), $\mathrm{V}_{\text {sedimented }}$ and $\mathrm{V}_{\text {sample }}$ are the extraction recovery, volume of the sedimented phase and volume of the sample, respectively. $\mathrm{C}_{\text {sedimented }}$ is calculated from a suitable direct injection calibration curve.

\section{Selection of the extraction solvent}

The selection of extraction solvent is a critical factor in DLLME. The extraction solvent must be immiscible with water, higher density than water and have high extraction capability for analytes. In our work, $\mathrm{CHCl}_{3}, \mathrm{CCl}_{4}$, $\mathrm{C}_{6} \mathrm{H}_{5} \mathrm{Cl}$ and $\mathrm{CS}_{2}$ were used as extraction solvents to analyze the effect of the solvent on extraction efficiency. A set of sample solutions was studied by using $1.0 \mathrm{~mL}$ of acetone containing different volumes of extraction solvents to achieve about $5.0 \mu \mathrm{L}$ volumes of settled phase, accordingly, 45.0, 13.0, 12.0 and $30.0 \mu \mathrm{L}$ volumes of $\mathrm{CHCl}_{3}, \mathrm{CCl}_{4}$, $\mathrm{C}_{6} \mathrm{H}_{5} \mathrm{Cl}$ and $\mathrm{CS}_{2}$ were selected, respectively. As shown in Figure $1, \mathrm{CS}_{2}$ possessed the highest extraction recovery as compared with other extraction solvents.

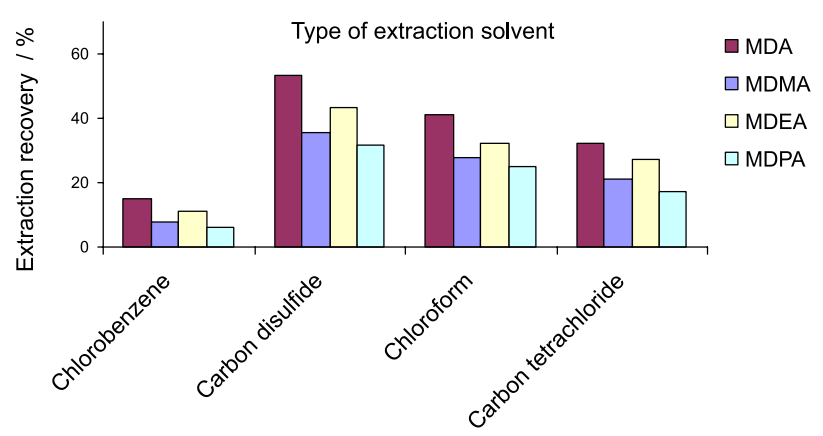

Figure1. Effect of type of extraction solvent on the extraction efficiency. Extraction conditions: sample volume of $5.0 \mathrm{~mL}$, disperser solvent (acetone) volume of $1.0 \mathrm{~mL}$, extraction solvent volumes of $45.0 \mu \mathrm{L}$ for $\mathrm{CHCl}_{3}, 12.0 \mu \mathrm{L}$ for $\mathrm{C}_{6} \mathrm{H}_{5} \mathrm{Cl}, 13.0 \mu \mathrm{L}$ for $\mathrm{CCl}_{4}, 30.0 \mu \mathrm{L}$ for $\mathrm{CS}_{2}$ and analyte concentration of $100 \mu \mathrm{g} \mathrm{L} \mathrm{L}^{-1}$.

\section{Selection of the disperser solvent}

For DLLME method, disperser solvent must be miscible in both water and the extraction solvent. Therefore, methanol, acetonitrile and acetone were tested as disperser solvents. The experiments were performed using $1.0 \mathrm{~mL}$ of each disperser solvent containing $30.0 \mu \mathrm{L}$ of $\mathrm{CS}_{2}$. The results illustrated in Figure 2 indicate that the variation of extraction recovery with different disperser solvent is not remarkable. Thus, acetone was chosen as the disperser solvent for subsequent experiments because of low cost and toxicity.

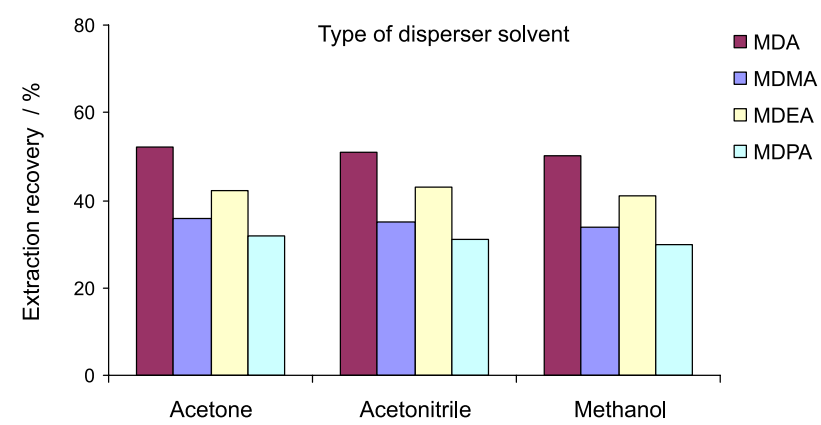

Figure 2. Effect of type of disperser solvent on the extraction efficiency. Extraction conditions: sample volume of $5.0 \mathrm{~mL}$, disperser solvent (acetone, acetonitrile and methanol) volume of $1.0 \mathrm{~mL}$, extraction solvent $\left(\mathrm{CS}_{2}\right)$ volume of $30.0 \mu \mathrm{L}$ and analyte concentration of $100 \mu \mathrm{g} \mathrm{L}^{-1}$.

\section{Effect of the extraction solvent volume}

To evaluate the effect of the extraction solvent volume on the extraction efficiency, a constant volume $(1.0 \mathrm{~mL})$ of acetone containing different volumes of $\mathrm{CS}_{2}(30.0-45.0 \mu \mathrm{L}$ at $5.0 \mu \mathrm{L}$ interval) was subjected to the same DLLME procedures. As shown in Figure 3, the preconcentration factor decreased on increasing the volume of extraction solvent because the volume of the settled phase was increased with the increase of $\mathrm{CS}_{2}$ volume. On the basis of these results, $30.0 \mu \mathrm{L}$ of $\mathrm{CS}_{2}$ was selected for subsequent experiments.

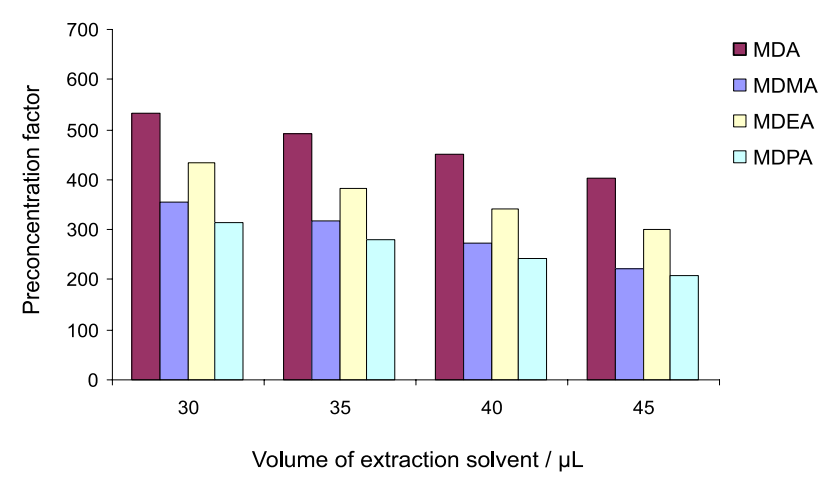

Figure 3. Effect of the extraction solvent $\left(\mathrm{CS}_{2}\right)$ volume on the preconcentration factor obtained from DLLME. Extraction conditions: sample volume of $5.0 \mathrm{~mL}$, disperser solvent (acetone) volume of $1.0 \mathrm{~mL}$, extraction solvent $\left(\mathrm{CS}_{2}\right)$ volumes of $30.0,35.0,40.0$ and $45.0 \mu \mathrm{L}$ and analyte concentration of $100 \mu \mathrm{g} \mathrm{L} \mathrm{L}^{-1}$.

\section{Effect of the disperser solvent volume}

To achieve a constant volume of settled phase $(5.0 \mu \mathrm{L})$, the volume of disperser and extraction solvents should 
also be changed simultaneously. To obtain the optimized volume of disperser solvent, various experiments were performed by using different volumes of acetone $(0.5,1.0$, 1.5 and $2.0 \mathrm{~mL}$ ) containing 28.0, 30.0, 35.0 and $40.0 \mu \mathrm{L}$ $\mathrm{CS}_{2}$, respectively. As can be seen from Figure 4, the extraction efficiency gradually increased with increasing disperser solvent, up to $1.0 \mathrm{~mL}$, but decreased with higher volumes. It may be due to that at low volume, acetone cannot disperse $\mathrm{CS}_{2}$ properly and cloudy solutions were not formed completely, and at high volumes, the solubility of analytes in water increased. So, $1.0 \mathrm{~mL}$ acetone was chosen as optimum volume.

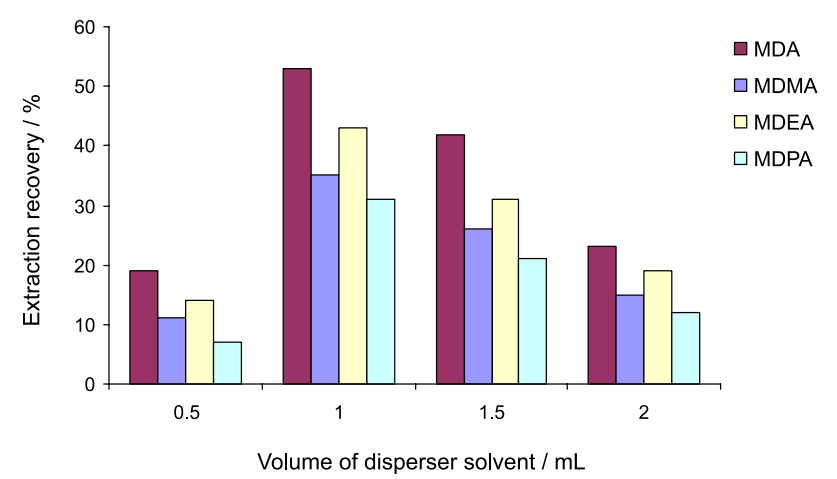

Figure 4. Effect of the disperser solvent (acetone) volume on the extraction recovery of analytes obtained from DLLME. Extraction conditions: sample volume of $5.0 \mathrm{~mL}$, disperser solvent (acetone) volumes of $0.5,1.0$, 1.5 and $2.0 \mathrm{~mL}$, extraction solvent $\left(\mathrm{CS}_{2}\right)$ volumes of 28.0, 30.0, 35.0 and $41.0 \mu \mathrm{L}$ and analyte concentration of $100 \mu \mathrm{g} \mathrm{\textrm {L } ^ { - 1 }}$.

\section{Effect of the $\mathrm{pH}$ of sample solution}

Obviously, $\mathrm{pH}$ value was the key parameter for sample solution affecting both the extraction efficiency and DLLME selectivity. The sample solution must be adjusted to a desired $\mathrm{pH}$ value in which the analytes were uncharged, thus the uncharged molecular form analytes were extracted into $\mathrm{CS}_{2}$ droplets effectively. The $\mathrm{pH}$ of samples was adjusted with $1 \mathrm{~mol} \mathrm{~L}^{-1}$ of $\mathrm{NaOH}$ to ensure that the neutral molecular forms of the analytes are present prior to the performing of the microextraction step. The effect of sample $\mathrm{pH}$ was tested in the $\mathrm{pH}$ range from 8 to 12 . The results show that the extraction recoveries of analytes were maximized at $\mathrm{pH} 10$ and then slightly decreased. Thus, $\mathrm{pH} 10$ was selected as the optimum value.

\section{Influence of extraction time}

The extraction time is defined as an interval time started after dispersion and ended just before centrifugation. The effect of time on the extraction efficiency was examined in the range of $0-20 \mathrm{~min}$. The results show that the extractiontime has no significant effect on the extraction efficiency of the analytes. It was revealed that the contact surface area between extracting solvent and sample solution was infinitely larger and equilibrium state was achieved after a few seconds. The comparison of equilibrium time of the proposed method and some other reported microextraction methods ${ }^{8,9}$ for the extraction of the target analytes indicates that this novel method has a very short equilibrium time as compared to the other extraction methods. Therefore, in further experiments, the centrifugation was carried out just after the dispersion process.

\section{Salt addition}

The effect of increasing the ionic strength of the sample was evaluated by adding $\mathrm{NaCl}(0-8 \%, \mathrm{~m} / \mathrm{v})$ into the sample solution. DLLME experimental conditions were the same as those described before. Plot of preconcentration factor $v s$. ionic strength is shown in Figure 5. It is clear that by increasing $\mathrm{NaCl} \%$, the volume of sedimented phase increased because of the decrease in solubility of the extraction solvent in the presence of salt. Preconcentration factor decreased because of increasing in the volume of sedimented phase (Figure 5). Therefore, further experiments were done without addition of salt.

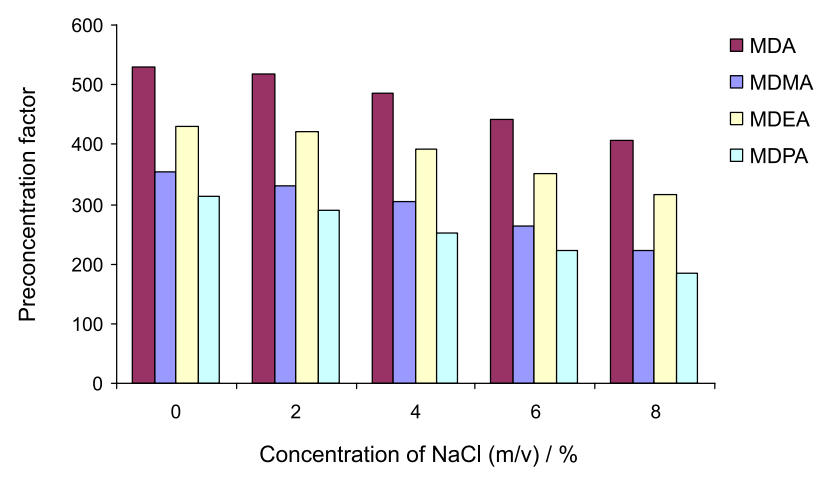

Figure 5. Effect of salt addition on the preconcentration factor of analytes obtained from DLLME. Extraction conditions: sample volume of $5.0 \mathrm{~mL}$, disperser solvent (acetone) volume of $1.0 \mathrm{~mL}$; extraction solvent $\left(\mathrm{CS}_{2}\right)$ volume of $30.0 \mu \mathrm{L}$ and analyte concentration of $100 \mu \mathrm{g} \mathrm{L} \mathrm{L}^{-1}$.

\section{Results and Discussion}

\section{Quantitative analysis}

In order to proceed with the current evaluation of the proposed DLLME technique, linearity, limit of detection (LOD) and repeatability were investigated under optimized conditions. The performance of the developed procedure is summarized in Table 1 . The calibration curves were linear in the range $2.5-500 \mu \mathrm{g} \mathrm{L}^{-1}$ for MDA and MDMA and 1.0-500 $\mu \mathrm{g} \mathrm{L^{-1 }}$ for MDEA and MDPA with correlation coefficients $\left(\mathrm{r}^{2}\right)$ ranging from 0.9968 to 0.9998 . The preconcentration factors were from 314 to 532 . LODs ( $\mathrm{S} / \mathrm{N}=3$, signal-to-noise ratio) 
were in the range from 0.3 to $0.8 \mu \mathrm{g} \mathrm{L} \mathrm{L}^{-1}$. Such detection sensitivity suggests a high potential for monitoring the target analytes on urine samples by DLLME-GC. RSDs (relative standard deviations) obtained after five consecutive extractions of analytes were calculated to be from 6.6 to $9.3 \%$. Extraction recovery (\%) and precisions (\%) at 5.0, 50 and $200 \mu \mathrm{g} \mathrm{L}^{-1}$ are listed in Table 2 for urine samples. Table 3 compares the proposed method with the other extraction methods for the determination of the target analytes in urine samples. The comparison of extraction time of the proposed method with $\mathrm{SPME}^{19}$ and microwave-assisted extraction (MAE) ${ }^{20}$ for the extraction of the target analytes indicates that this novel method has a very short equilibrium time comparing to the mentioned methods and the extraction time needed for the proposed method is a few seconds and quantitative results of the proposed method are better than those for SPME and MAE methods. Quantitative results of the proposed method are comparable with DLLME-capillary electrophoresistime-of-flight mass spectrometry ${ }^{21}$ without using MS as a sensitive detector. The quantitative results of the proposed method are better than those for molecularly imprintedsolid phase extraction with simultaneous derivatization and DLLME-GC-FID ${ }^{22}$ without using derivatization.

\section{Analysis of real samples}

The proposed DLLME-GC procedure described above was applied to determine the target analytes in urine and water samples. Human blank urine was taken from healthy volunteers. All the volunteers declared they had not used amphetamine. Blank samples of urine were spiked with a mixture of the compounds of interest at the requested concentration by adding standard methanolic solutions. In order to determine if analytes is in human urine, the urine from a healthy individual was collected in disposable polyethylene containers and kept at $4{ }^{\circ} \mathrm{C}$ before analysis. In order to reduce the matrix effect, the urine sample was diluted to $1: 5$, using deionized water. Typical chromatograms obtained for the urine samples before and after spiking of the target analytes by using the DLLME method under the optimum conditions are shown in Figure 6. To determine the matrix effect on the extraction procedures, the relative recoveries of samples spiked with known amounts of each drug were investigated. The results obtained are summarized in Table 4 . The relative recoveries of the proposed method for the determination of the target analytes were in the range $90-98.5 \%$ in urine. These results demonstrated that the urine matrices had little effect on

Table 1. Quantitative results of DLLME and GC-FID of MDA, MDMA, MDEA and MDPA ${ }^{a}$

\begin{tabular}{|c|c|c|c|c|c|}
\hline & & ear rang & $/(\mu \mathrm{g} \mathrm{I}$ & & \multirow{2}{*}{ LOD / $\left(\mu \mathrm{g} \mathrm{L}^{-1}\right)$} \\
\hline & $\overline{\mathrm{MDA}}$ & MDMA & MDEA & MDP & \\
\hline
\end{tabular}

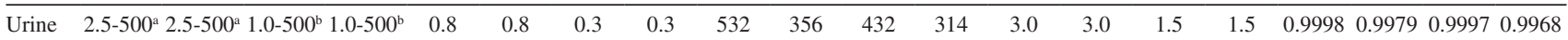

LOD: limit of detection for $\mathrm{S} / \mathrm{N}=3$ (signal-to-noise ratio); PF: preconcentration factor; LOQ: limit of quantitation; $\mathrm{r}^{2}$ : correlation of coefficient; aight concentration points; bnine concentration points.

Table 2. Extraction recovery and precision at three concentration levels of MDA, MDMA, MDEA and MDPA

\begin{tabular}{|c|c|c|c|c|c|c|c|c|c|c|c|c|c|c|c|c|c|c|c|c|c|c|c|c|}
\hline \multirow{3}{*}{ Urine } & \multicolumn{12}{|c|}{ Extraction recovery / \% } & \multicolumn{12}{|c|}{ Precision $/ \%, \mathrm{n}=4$} \\
\hline & \multicolumn{3}{|c|}{ MDA } & \multicolumn{3}{|c|}{ MDMA } & \multicolumn{3}{|c|}{ MDEA } & \multicolumn{3}{|c|}{ MDPA } & \multicolumn{3}{|c|}{ MDA } & \multicolumn{3}{|c|}{ MDMA } & \multicolumn{3}{|c|}{ MDEA } & \multicolumn{3}{|c|}{ MDPA } \\
\hline & $5.0^{\mathrm{a}}$ & $50^{\mathrm{a}}$ & $200^{\mathrm{a}}$ & $5.0^{\mathrm{a}}$ & $50^{\mathrm{a}}$ & $200^{\mathrm{a}}$ & $5.0^{\mathrm{a}}$ & $50^{\mathrm{a}}$ & $200^{\mathrm{a}}$ & $5.0^{\mathrm{a}}$ & $50^{\mathrm{a}}$ & $200^{\mathrm{a}}$ & $5.0^{\mathrm{a}}$ & $50^{\mathrm{a}}$ & $200^{\mathrm{a}}$ & $5.0^{\mathrm{a}}$ & $50^{\mathrm{a}}$ & $200^{\mathrm{a}}$ & $5.0^{\mathrm{a}}$ & $50^{\mathrm{a}}$ & $200^{\mathrm{a}}$ & $5.0^{\mathrm{a}}$ & $50^{\mathrm{a}}$ & $200^{\mathrm{a}}$ \\
\hline & 50.4 & 52.1 & 55.1 & 32.6 & 33.4 & 37.4 & 39.5 & 41.6 & 45.2 & 27.1 & 29.6 & 33.2 & 7.8 & 8.2 & 4.3 & 10.6 & 9.7 & 6.6 & 9.1 & 8.4 & 5.6 & 11.5 & 10.1 & 7.3 \\
\hline
\end{tabular}

${ }^{\mathrm{a}}$ Concentration $\left(\mu \mathrm{g} \mathrm{L}{ }^{-1}\right)$.

Table 3. Comparison of the proposed method with other extraction methods for determination of the target analytes in urine

\begin{tabular}{|c|c|c|c|c|c|c|}
\hline Method & $\mathrm{EF}$ & RSD / \% & $\begin{array}{l}\text { Dynamic linear } \\
\text { range / }\left(\mu \mathrm{g} \mathrm{L} \mathrm{L}^{-1}\right)\end{array}$ & $\begin{array}{l}\text { LOD / } \\
\left(\mu \mathrm{g} \mathrm{L}^{-1}\right) \\
\end{array}$ & $\begin{array}{c}\text { Extraction time / } \\
\text { min }\end{array}$ & Reference \\
\hline $\begin{array}{l}\text { DLLME-capillary electrophoresis-time- } \\
\text { of-flight mass spectrometry }\end{array}$ & 133 & - & - & $025-0.50$ & a few seconds & 19 \\
\hline $\begin{array}{l}\text { Moleculary imprinted-solid phase } \\
\text { extraction with simultaneous } \\
\text { derivatization and DLLME-GC-FID }\end{array}$ & 285 & 6.8 & $50-1500$ & 18 & a few seconds & 20 \\
\hline Solid-phase microextraction-GC-MS & - & $\leq 14.3$ & $100-10000$ & $5.0-15.0$ & 16 & 21 \\
\hline Microwave-assisted extraction-GC-FID & - & $5.5-6.9$ & $50-15000$ & $10-20$ & 10 & 22 \\
\hline DLLME-GC-FID & $314-532$ & $8.2-10.1$ & $1.0-500$ & $0.3-0.8$ & seconds & this work \\
\hline
\end{tabular}

RSD: relative standard deviation; LOD: limit of detection; PF: preconcentration factor. 
Table 4. Determination of MDA, MDMA, MDEA and MDPA in water and urine samples and relative recovery of spiked MDA, MDMA, MDEA and MDPA in water and urine samples

\begin{tabular}{|c|c|c|c|c|c|c|c|c|c|c|c|c|c|c|c|c|}
\hline \multirow{2}{*}{ Sample } & \multicolumn{4}{|c|}{ Concentration / $\left(\mu \mathrm{g} \mathrm{L}^{-1}\right)$} & \multicolumn{4}{|c|}{ Added / $\left(\mu \mathrm{g} \mathrm{L}^{-1}\right)$} & \multicolumn{4}{|c|}{ Found $\pm \mathrm{SD} /\left(\mu \mathrm{g} \mathrm{L}^{-1}\right), \mathrm{n}=3$} & \multicolumn{4}{|c|}{ Relative recovery $/ \%$} \\
\hline & MDA & MDMA & MDEA & MDPA & MDA & MDMA & MDEA & MDPA & MDA & MDMA & MDEA & MDPA & MDA & MDMA & MDEA & MDPA \\
\hline 0 & n.d. & n.d. & n.d. & n.d. & 7.0 & 7.0 & 7.0 & 7.0 & $6.6 \pm 0.4$ & $6.7 \pm 0.5$ & $6.8 \pm 0.6$ & $6.9 \pm 0.7$ & 94.2 & 95.7 & 97.1 & 98.5 \\
\hline Jrine $^{\mathrm{a}}$ & n.d. & n.d. & n.d. & n.d. & 3.0 & 3.0 & 3.0 & 3.0 & $2.7 \pm 0.2$ & $2.8 \pm 0.2$ & $2.7 \pm 0.3$ & $2.9 \pm 0.3$ & 90 & 93.3 & 90 & 96.6 \\
\hline
\end{tabular}

${ }^{a}$ From healthy person urine; n.d.: not detected.

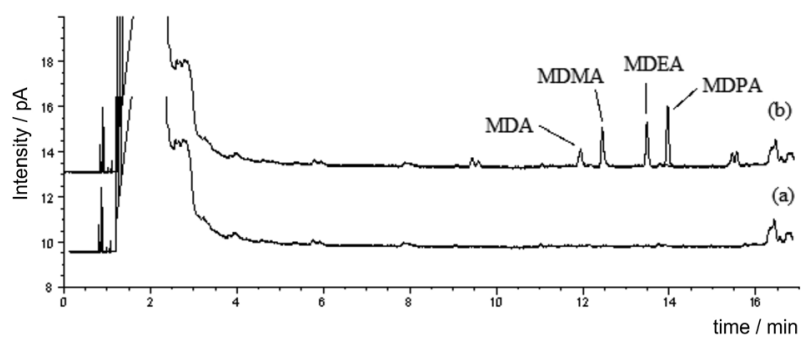

Figure 6. GC-FID chromatograms of (a) before spiking with analytes in urine and (b) $3.0 \mu \mathrm{g} \mathrm{L}^{-1}$ spiked of analytes in urine after extraction via the proposed method at optimum conditions. Extraction conditions are the same as in Figure 5.

the DLLME method. The obtained results indicate the feasibility of the DLLME method for the determination of the target analytes in urine samples.

\section{Conclusions}

This study demonstrates the successful application of DLLME-GC-FID method for the determination of MDA, MDEA, MDMA and MDPA in urine samples. The optimum conditions of extraction performance were obtained. The experimental results reveal that this method provides relatively high extraction efficiencies within a short time, low LOD and good linearity over the investigated concentration range. The performance of this procedure in the extraction of the target analytes from urine was satisfactory. Compared with $\mathrm{SPME}^{8,9}$ for the extraction and determination of target analytes, in addition to the short extraction time, low cost and feasibility, the best advantages of the present method are its good linearity and repeatability. Therefore, it has the potential to be a powerful tool for the analysis of the target analytes in urine samples.

\section{Acknowledgements}

Financial support by Tonekabon Branch, Islamic Azad University (Tonekabon, Iran) for the support during the period of this research is gratefully acknowledged.

\section{References}

1. Pickering, H.; Stimson, G. V.; Addiction 1999, 89, 1385.
2. Cheng, L. T.; Kim, S. Y.; Chung, A.; Castro, A.; FEBS Lett. 1973, 36, 339.

3. Taylor, R. W.; Sam, D. L.; Philip, S.; Jain, N. C.; J. Anal. Toxicol. 1989, 13, 293.

4. Shin, H. S.; Donike, M.; Anal. Chem. 1996, 68, 3015.

5. Lee, E. D.; Henion, J. D.; Brunner, C. A.; Wainer, I. W.; Doyle, T. D.; Gal, J.; Anal. Chem. 1986, 58, 1349.

6. Bienvenida, G. L.; Garcia-Reyes, J. F.; Antonio, M. D.; Talanta 2009, 79, 109.

7. Feas, X.; Seijas, J. A.; Vazquez-Tato, M. P.; Regal, P.; Cepeda, A.; Fente, C.; Anal. Chim. Acta 2009, 631, 237.

8. Ugland, H. G.; Krogh, M.; Rasmussen, K. E.; J. Pharm. Biomed. Anal. 1999, 19, 463.

9. Ugland, H. G.; Krogh, M.; Rasmussen, K. E.; J. Chromatogr., B Anal. Technol. Biomed. Life Sci. 1997, 701, 29.

10. Helena, P.; Locita, L. K.; TrAC, Trends Anal. Chem. 1999, 18, 272.

11. Rezaee, M.; Assadi, Y.; Milani Hosseini, M. R.; Aghaee, E.; Ahmadi, F.; Berijani, S.; J. Chromatogr., A 2006, 1116, 1.

12. Rezaee, M.; Yamini, Y.; Faraji, M.; J. Chromatogr., A 2010, 1217, 2342.

13. Rezaee, M.; Yamini, Y.; Shariati, S.; Esrafili, A.; Shamsipur, M.; J. Chromatogr., A 2009, 1216, 1511.

14. Mashayekhi, H. A.; Abroomand-Azar, P.; Saber-Tehrani, M.; Waqif, S. H.; Chromatographia 2010, 71, 517.

15. Mashayekhi, H. A.; Abroomand-Azar, P.; Saber-Tehrani, M.; Waqif, S. H.; Int. J. Environ. Anal. Chem. 2011, 91, 516.

16. Mashayekhi, H. A.; Rezaee, M.; Sadeghi Garmaroudi, S.; Montazeri, N.; Ahmadi, S. J.; Anal. Sci. 2011, 27, 865.

17. Guo, J.; Li, X.; Cao, X.; Li, Y.; Wang, X.; Xu, X.; J. Chromatogr., A 2009, 1216, 3038.

18. Zhao, R.; Diao, C.; Chen, Q.; Wang, X.; J. Sep. Sci. 2009, 32, 1069.

19. Kohler, I.; Schappler, J.; Sierro, T.; Rudaz, S.; J. Pharm. Biomed. Anal. 2012, DOI: 10.1016/j.jpba.2012.03.036.

20. Djozan, D.; Farajzadeh, M. A.; Sorouraddin, S. M.; Baheri, T.; J. Chromatogr., A 2012, 1248, 24.

21. Ugland, H. G.; Krogh, M.; Rasmussen, K. E.; J. Pharm. Biomed. Anal. 1999, 19, 463.

22. Ye, N.; Gu, X.; Wang, J.; Sun, H.; Li, W.; Zhang, Y.; Chromatographia 2009, 69, 933. 